\title{
Understanding Eurasian Convergence: Application Of Kohonen Self-Organizing Maps
}

Joel I. Deichmann

Bentley College

Abdolreza Eshghi

Dominique Haughton

Selin Sayek

Nicholas Teebagy

See next page for additional authors

Follow this and additional works at: http://digitalcommons.wayne.edu/jmasm

Part of the Applied Statistics Commons, Social and Behavioral Sciences Commons, and the Statistical Theory Commons

\section{Recommended Citation}

Deichmann, Joel I.; Eshghi, Abdolreza; Haughton, Dominique; Sayek, Selin; Teebagy, Nicholas; and Topi, Heikki (2006)

"Understanding Eurasian Convergence: Application Of Kohonen Self-Organizing Maps," Journal of Modern Applied Statistical Methods:

Vol. 5 : Iss. 1 , Article 8.

DOI: $10.22237 /$ jmasm/1146456420

Available at: http://digitalcommons.wayne.edu/jmasm/vol5/iss1/8

This Regular Article is brought to you for free and open access by the Open Access Journals at DigitalCommons@WayneState. It has been accepted for inclusion in Journal of Modern Applied Statistical Methods by an authorized editor of DigitalCommons@WayneState. 


\section{Understanding Eurasian Convergence: Application Of Kohonen Self- Organizing Maps}

Authors

Joel I. Deichmann, Abdolreza Eshghi, Dominique Haughton, Selin Sayek, Nicholas Teebagy, and Heikki Topi 


\section{Understanding Eurasian Convergence: Application Of Kohonen Self-Organizing Maps}

\author{
Joel I. Deichmann \\ Selin Sayek
}

\author{
Abdolreza Eshghi \\ Nicholas Teebagy
}

Dominique Haughton

Heikki Topi

Data Analytics Research Team, Bentley College

Kohonen self-organizing maps (SOMs) are employed to examine economic and social convergence of Eurasian countries based on a set of twenty-eight socio-economic measures. A core of European Union states is identified that provides a benchmark against which convergence of post-socialist transition economies may be judged. The Central European Visegrád countries and Baltics show the greatest economic convergence to Western Europe, while other states form clusters that lag behind. Initial conditions on the social dimension can either facilitate or constrain economic convergence, as discovered in Central Europe vis-à-vis the Central Asian Republics. Disquiet in the convergence literature is resolved by providing an analysis of the Eurasian states over time.

\section{Introduction}

The definition of what constitutes the entity of Europe is debated widely (Almström, 2000;

Joel Deichmann is Associate Professor of Geography. His research interests include Foreign Direct Investment. Abdolreza Eshghi is Professor of Marketing and Director for the Center for Marketing Technology. His research interests focus on customer relationship management. Dominique Haughton is Professor of Mathematical Sciences. Her areas of research include analyses of living standards in developing countries. Selin Sayek is Professor of Economics, Bilkent University, Turkey. Her research focuses on foreign direct investment and aid flows. Nicholas Teebagy, in memoriam, was Associate Professor of Mathematical Sciences. His research interests are in spline analyses of ozone data and finance. Dr. Heikki Topi is Associate Professor of Computer Information Systems and Director of the MSIT Program. His research focuses on human factors and usability issues in enterprise systems. Kohonen maps appear in this article in gray scale. See the JMASM web site (http://tbf.coe.wayne.edu/jmasm) for renditions of these maps in color.
Jordan, 2002). In particular, no satisfactory physiographic barriers exist to distinguish Europe from neighboring Asia. Many scholars approximate the border as the Ural Mountains, the Volga River, or the Bosporus Strait, dividing Russia and Turkey between Europe and Asia (Jordan, 2002). Others conveniently define Europe according to the membership of the fifteen EU member states, but this definition leaves out Norway, Switzerland, and several wealthy micro-states, as well as (until 2004) the Central European candidate states. Jordan (2002) defined Europe in terms of the people who live there, identifying the cultural traits that define the source of Western civilization, in addition to ten secondary socio-economic characteristics that most European states share.

The collapse of the Soviet empire in 1989, coupled with the deepening and widening debate within the EU, has fueled an unprecedented movement toward a unified Europe. The post-socialist countries of Central and Eastern Europe have embarked upon a daunting task of instituting a series of dramatic economic and social reforms to create westernstyle market economies with the objective of becoming full-fledged members of the EU as quickly as possible. As noted by the Economic Analysis Division of the United Nations Economic Commission for Europe: 
One of the strategic goals of the transition economies is to achieve sustained and high rates of economic growth that would enable them to catch up with - to converge upon - the living standards of the developed economies of Western Europe. And many of them regard EU membership as instrumental to promote this process. (United Nations Economic Commission for Europe, 2000)

In their efforts to join the EU, Central and Eastern European countries have opted for a wide variety of transition paths to treat their unique set of initial conditions, in turn leading to a correspondingly heterogeneous set of results. While some have either regained (e.g., Poland, Slovakia, and Slovenia) or are close to regaining (Czech Republic and Hungary) their pretransition GDP levels, others (notably Georgia, Ukraine, and Moldova) continue to struggle with their transformational recession (United Nations Economic Commission for Europe, 2000).

The question of post-socialist convergence has been the subject of extensive scholarly research from various perspectives (see Szalkowski \& Jankowicz, 1999; Genov, 1998; Bartlett, 1997; Brabant, 1998; Lang, 2003; Graham \& Hart, 1999, to name just a few). However, there is no consensus on the extent of convergence and the factors that have led to highly heterogeneous outcomes. The research presented here is intended to address these issues by analyzing a comprehensive set of socioeconomic variables for all of the Western European and post-Communist countries for which data are available.

More specifically, the purpose of this article is to map the progress of post-socialist countries in catching up with, or converging upon the advanced Western European economies over the past decade. In particular, not only is the overall convergence mapped, but the macroeconomic, social, and institutional factors that are responsible for the convergence, or lack thereof, are identified. In this context, the role played by economic factors versus social factors in catching up and converging with the EU is discussed. A secondary purpose of this research is to extend previous Kohonen analysis on transition economies (Deichmann et al.,
2003) to include the existing EU members plus Norway, Switzerland, the USA (see note 1 in Fig.9), and Turkey. In so doing, it is hoped that the extent to which this broader group of Eurasian states clusters geographically when all reference to location is absent will be determined, and use the changes in the clusters over time to observe whether or not patterns of convergence exist among these groups of economies.

Post-Socialist Heterogeneity

A significant body of literature has documented the differential levels of convergence throughout Eurasia during the first ten years after the Iron Curtain fell. Using data through 1998, Estrin, Urga, and Lazarova (2001) examine average (GDP) growth rates for transition economies leading up to and following the abrupt changes that began in the early 1990s. Focusing upon twenty-six countries over twentyseven years, the level of pre-transition convergence was examined since 1991. Among the twenty-six states, they found that Hungary, Poland, Slovenia, Estonia, and Armenia are the only states with positive average growth rates since the transition and only Armenia, Slovenia, and Hungary have sustained growth that might eventually allow their economies to catch up with those of Western Europe.

Also citing disparities in growth prior to the 1990s transition, the authors highlight the failure of reallocation mechanisms within the Soviet bloc, with the possible exception of the former Yugoslavia, which was only loosely affiliated with Moscow. They concluded that the failure of Soviet-led central planning to ameliorate regional disparities within the socialist bloc is likely to have facilitated the demise of supranational affiliations within the region. Unfortunately, the authors also find little evidence for convergence during the first decade of individual state policies.

Kočenda (2001) modeled the time-path of several macroeconomic variables to evaluate convergence of Central European and Baltic states. Variables under investigation include industrial output, prices, money (capital), and interest rates. Among these countries, there are dramatically differing initial conditions that favor the Czech Republic and its neighbors, 
while putting the Baltic states at a comparative disadvantage; for example, the former enjoy an earlier 1989 starting point, while the latter became independent in 1991 and have only recently introduced their own new currencies. Despite the countries' unique initial conditions, Kočenda (2001) found considerable evidence of convergence by these otherwise similar countries through the natural process of increased international trade and through the institutional processes of coordination to satisfy EU pre-accession requirements. However, Kutan and Yigit (2004) emphasized the importance of model specification and how it changes the results of Kočenda (2001). They showed that when heterogeneity is taken into account the within-group convergence is not as evident as suggested by Kočenda.

Brada and Kutan (2001) examined the extent of convergence of monetary policy of EU candidate and non-candidate transition states to the German monetary policy, which is viewed to be broadly representative of the European Central Bank. They concluded that the transition states (both candidate and non-candidate) lag far behind the non-transition EU candidates (Cyprus, Malta, and Turkey), revealing deeply rooted disadvantages of central planning that endure in transition countries. They contended that Hungary and Poland, which have pursued independent monetary policies throughout the 1990s, have the best prospects of converging to EU fiscal policies.

Brada, Kutan, and Zhou (2002) employed a rolling cointegration technique to evaluate the convergence of base money, broader money (M2), the consumer price index (CPI), and industrial output in five leading EU candidate countries: the Czech Republic, Estonia, Hungary, Poland, and Slovenia. Brada et al. (2002) argue that adequate convergence has yet to occur in the areas of monetary policy and industrial output, but that consumer prices and M2 are comparable to those in the EU, confirming earlier findings (Brada \& Kutan, 2001) with a wider frame of inquiry. They concluded that considerable time will be necessary following accession and before the candidates join the Euro zone.

Wagner and Hlouskova (2001) focused on convergence in the real (vis-à-vis nominal) dimension, mainly economic growth. In doing so, they study the correlation between the initial level of GDP of ten Central and Eastern European economies and their average growth rates over the 1990s and find evidence for convergence only after 1998. They applied the distributional dynamics technique, formulating a statistical model to describe the evolution of the joint distribution of real per capita GDP of the CEE and EU economies. This method allows for the investigation of the mobility of each economy within the cross country income distribution over time. They concluded that their evidence reveals high persistence in the data combined with a low probability of an economy changing its location in the distribution. Therefore, neither of their methods suggested evidence of convergence among the CEE and EU economies through 1998.

Theoretical Explanation

The issue of heterogeneity in economic convergence among post-socialist countries can be explained with reference to a number of theoretical and conceptual arguments. First, theoretical models in development economics (Barro \& Sala-i Martin, 1992) posited that economies with low initial GDP levels should grow faster than those with higher initial GDP levels, and eventually catch up with these more developed economies. This is certainly the case among post-socialist countries. These countries began the journey toward a free-market economy with varying initial economic conditions.

A second explanation was offered by Romer (1986) who argued that the characteristics inherent in technology prevent convergence from occurring because increasing returns to scale cause the rich countries to become richer while the poor countries fall further behind. A related argument is that convergence will only occur among countries with a well-developed human capital base, which allows for such countries to benefit from modern technology.

Third, Barro (1991) and Barro and Salai Martin (1992) suggested that absolute convergence does not exist as all countries have different long-run per capita income levels that prevent such convergence. However, they 
showed that each country converges to these differing long-run equilibria, and they labeled this phenomenon as conditional convergence.

Fourth, Sachs and Warner (1995) argued that unconditional convergence depends upon the policy choices of the respective economies, and that countries that pursue market-based economic policies, liberal trade policies, and respect private property rights show strong tendencies to convergence. Sachs and Warner (1995) found that the transition economies that have undertaken significant economic reforms show convergence signs to the European Union, while those that have not converged show persistence in their economic position.

Fifth, the specific manner of implementing economic reforms is also believed to be responsible for heterogeneous patterns of convergence. Some countries opted primarily for a top-down approach by privatizing the stateowned enterprises, whereas others (mainly the Central and Eastern European economies) generally favored a bottom-up approach by encouraging the establishment of new start-up enterprises and development of existing private firms (Brezinski \& Fritsch, 1996; Woo, 1998). Ellman (1997) argued that experience from the past decade demonstrates that the development of new private firms is more important for the resumption of economic growth than is rapid privatization.

Another factor that may have influenced the convergence outcome is the pace at which reforms were implemented. Some countries implemented drastic macroeconomic stabilization policies known as the shock therapy approach, whereas others insisted upon a policy of gradualism, which entails structural and institutional reforms as a pre-condition to introducing macroeconomic stabilization reforms (Popov, 2000).

Finally and perhaps most importantly, the success of economic and social reforms is not only contingent upon their contents but upon the social and historical context in which they are implemented (Rosenbaum, 2001). In other words, market reforms presuppose societal values and norms that are consistent with democracy and a free-market economy. Some post-socialist countries have been more successful in implementing market reforms due to their historical and cultural ties with Western Europe. Rosenbaum's (2001) review of the economic history of Central and Eastern Europe indicates that the development of a secular civil society in Western and Central Europe resulted from conflict between the state and the princes on the one hand and the church on the other. Consequently, the intellectuals gained the opportunity to play off competing authorities against one another, giving rise to new philosophical and political ideas that led to the overthrow of the autocratic and feudal order and relegated the church to just one of many interest groups. By contrast, the church and the political authority remained in one hand in the East under Orthodoxy, which tended to block individualistic tendencies and the introduction of new ideas such as private property.

As also noted in Rosenbaum (2001, p. 895), whereas Christianized Poles, Czechs, and Hungarians adopted the institutional order of the West and became part of Western culture, Russia and much of the Balkan region remained insulated from the infusion of new ideas, leading to consolidation of power in the hands of the state. As a consequence, Orthodox cultures tend to accept the dominant role of the state in society and economy as fait accompli. Clearly, the historical experiences of post-socialist countries have far reaching implications for the role of the individual in determining her/his economic destiny. In short, when the historical and cultural experiences are consistent with free market values and norms, substantial progress toward convergence is observed over a relatively short period of time. However, when there is a mismatch between the historical and cultural experiences and the free market values and norms, the transition is likely to be slow and painful.

\section{Methodology}

Kohonen Self-organizing maps were used (SOMs) to examine post-socialist convergence in Eurasian countries. Kohonen maps were pioneered during the 1980s and have been used as a method of visualizing non-spatial data (Kohonen, 1982). Techniques for creating and interpreting Kohonen maps have been refined and reviewed by their namesake in a series of 
subsequent volume editions (Kohonen, 2001). SOMs have been employed in many contexts, for example in mapping non-geographic data ranging from text documents (Kohonen, 1999) to conference abstracts (Skupin, 2002; Kloptchenko et al., 2003).

The application of Kohonen maps continues to grow in a variety of disciplines (Deboeck, 1998; Oja \& Kaski, 1999). One application that is particularly relevant here is the work of Costea, Kloptchenko, and Back (1998). They compared the relative advantages of SOMs and cluster analysis in evaluating the economic status of six transition economies: Russia, Ukraine, Romania, Poland, Slovenia, and Latvia. They introduced a very insightful way of depicting statistical trends in data over time: each observation corresponds to a country at a specific point in time, which facilitated a clear understanding of how countries migrate across the map over time.

\section{The Kohonen Algorithm}

The Kohonen algorithm can be briefly described as follows (see for example Kaski and Kohonen 1996): the algorithm assigns to each position $i$ in a grid an arbitrary (random) vector $m_{i}(0)$ with as many components as input variables. At each time $t$ the vector of variables $x(t)$ corresponding to one of the observations updates the current vectors $m_{i}(t)$ according to the formula $m_{i}(t+1)=m_{i}(t)+h_{c i}(t)\left(x(t)-m_{i}(t)\right)$, where $c=\arg \min _{i}\left(\left\|x-m_{i}\right\|\right)$ and $\quad h_{i j}(t)$ is a function of $t$ and of the geometric distance on the lattice between position $i$ and position $j$. Typically $h_{i j} \rightarrow 0$ with increasing distance between $i$ and $j$ and increasing time. So the vector $x(t)$ is allowed to update the vector $m_{c}(t)$ it is closest to as well as some neighboring vectors $m_{i}(t)$. When the algorithm converges, the $m_{i}$ tend to be ordered along the lattice in a meaningful way (see note 2 in Fig. 9).

\section{Data Issues}

Due to data restrictions, the analysis is limited to the period 1992-2000. The breakups of the Soviet Union, Yugoslavia, and
Czechoslovakia all resulted in missing values for the resulting new states during the early years of our analysis. These were addressed by entering the unions' values for each state (for example, the Czech Republic and Slovakia were both assigned the 1992 value for Czechoslovakia). After that point, any missing entries were replaced with the value estimated by regressing each variable on time for each country. Finally, many missing values for the year 2001 limited the analysis to the years through 2000 .

Description of Variables

Procuring accurate, complete, and current socioeconomic data for the transition states is a formidable challenge (Costea, Kloptchenko, \& Back, 2001). Most of the data were collected by national authorities and reported by the World Bank Development Indicators CD-ROM (2002) for the years 19922000.

The list of variables under consideration is presented in Table 1. The variables include economic, social, and political measures. The measures were chosen to capture each country's preconditions as well as subsequent measures (both absolute numbers and rates of change). The economic variables can be sub-grouped into real and nominal variables. The real variables encompass indicators of economic development, the role of government and fiscal policy in the economy, the level of physical infrastructure, the depth of financial markets, and international openness measures. The nominal variables include indicators regarding the domestic price of goods and the foreign currency price of the domestic currency, the inflation rate and the real exchange rate respectively, and the real interest rates. Explicit reform variables, as addressed by Sach and Warner (1995), are available only for transition states, and are therefore unsuitable for this analysis that spans the EU and other wealthy states as well.

The social infrastructure measures, which include variables that impact the development of human capital, such as education and health measures, are covered in the social dimension of the analysis. In addition to such social infrastructure measures several physical infrastructure measures are also 
included in this group, as they also contribute

more to the development of social infrastructure

TABLE 1. List OF ECONOMIC, SOCIAL, AND POLITICAL VARIABLES

\begin{tabular}{l|l}
\hline Variable & Description \\
\hline Prscgdp & Private sector credit as share of GDP \\
Electricyt & Electric power transmission and distribution losses \\
Kgdp & Gross capital formation as share of GDP \\
Infl & Inflation (GDP deflator based) \\
Growth & Real GDP per capita growth \\
Tradegdp & Trade as a share of GDP \\
Figdp & FDI as a share of GDP \\
Reserves & Reserves, months of import coverage \\
Cagdp & Current account balance as a share of GDP \\
Gdppc & GDP per capita (in real 1995 USD) \\
Fiscgdp & Overall fiscal balance including grants (share of GDP) \\
Rer & Real exchange rate \\
Rir & Real interest rate \\
Bankresliq & Bank reserves to liquid assets \\
Tellines & Telephone lines (per 1000) \\
Stuteach & Student to teacher ratio \\
Schoolenroll & Secondary school enrollment (gross) \\
Immunmeasl & Immunization against measles \\
Lifeexp & Life expectancy \\
Nodoctors & Number of physicians (per 1000) \\
Immunization & Immunization against DPT \\
Agedepend & Age dependency ratio (dependents to working-age population) \\
Healthpub & Public health expenditures (share of GDP) \\
Healthpr & Private health expenditures (share of GDP) \\
Healthsum & Total health expenditures (share of GDP) \\
Internet & Internet users as share of population \\
Civlib & Score for civil liberties (1=lowest, 7=highest)* \\
Polrights & Score for political rights (1=lowest, 7= highest)* \\
\end{tabular}

Data Source: World Bank (2002) except for *, which were obtained from Freedom House (2003)

than anything else. These measures include efficiency in electricity distribution and access to communication means such as telephone and the internet. Finally, the social indicators also include measures of extent of political rights and civil liberties.

\section{Analysis}

As in Costea, Kloptchenko, and Back (2001), all countries under investigation for each individual year are first plotted on a single map to monitor movements over time throughout the lattice on the basis of all available variables. The variables are then subdivided into social/political and economic measures in an effort to examine the role they play in convergence.
Analysis of Aggregate Maps

Figure 1 represents a self-organizing map of all country-year pairs (such as Moldova 1992, for example) over 1992-2000, constructed on the basis of all variables in Table 1 for all countries under investigation. The largest group of countries can be thought of as a European core-composed of mainly EU states located in the center-top of the figure (such as France, Germany, Ireland, Luxembourg, the Netherlands, the UK). Outside this core, several noteworthy peripheries exist, in addition to several distinct groups of laggard transition countries. As was observed in past work (Kaski \& Kohonen, 1996; Deichmann et al., 2003), an 
outstanding feature of this first U-matrix is the preservation of many geographic relationships

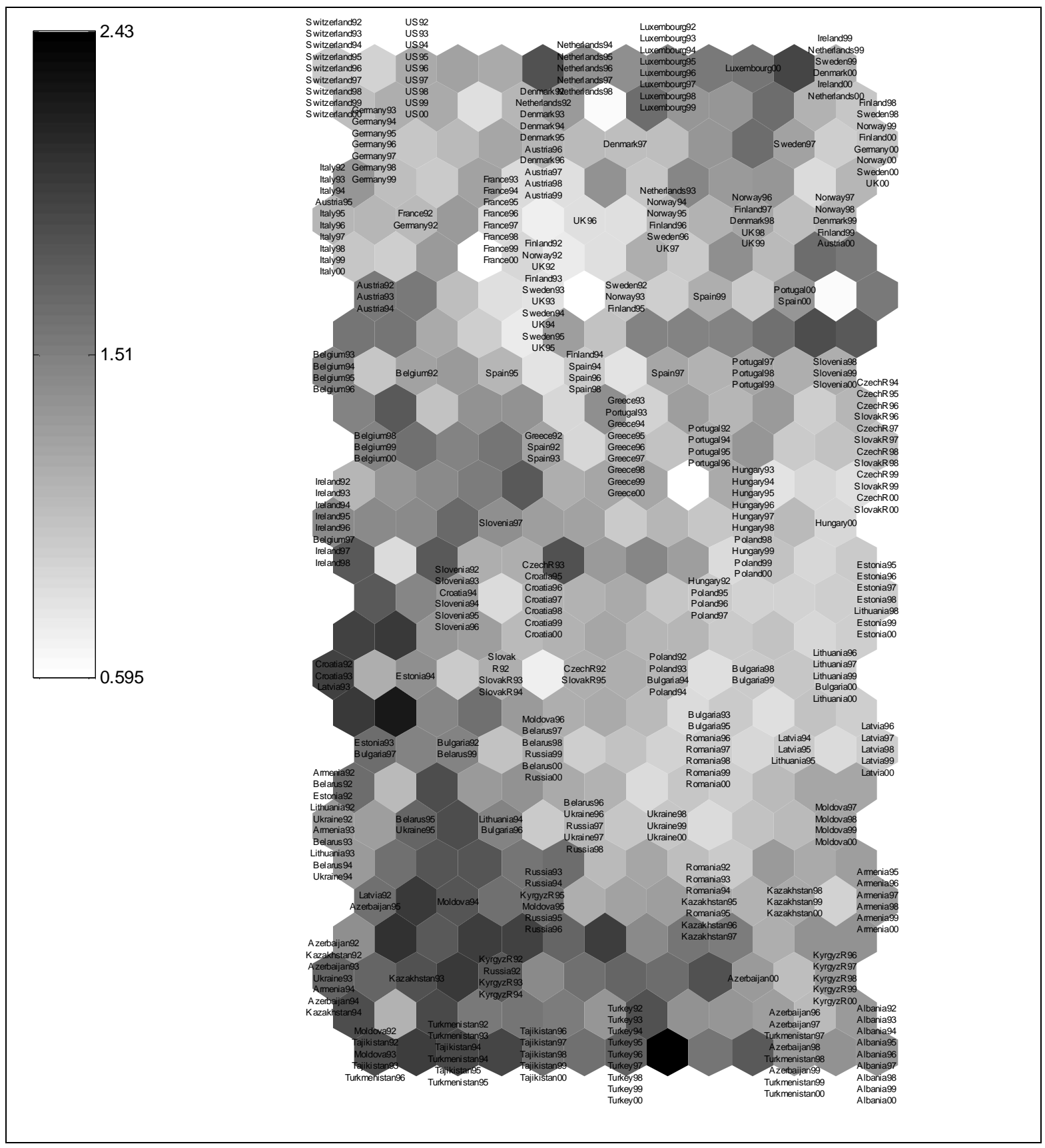

FIGURE 1. U-MATRIX OF COUNTRY MOVEMENTS FROM 1992-2000.

Note: See http://tbf.coe.wayne.edu/jmasm for map in color. 
in the absence of explicitly geographic variables. This is clearly the case in Figure 1 and in subsequent figures.

Figure 2 provides estimated (by the Kohonen algorithm) values of the input variables at each grid position in the U-matrix. For example, it may be seen that estimated values of private health expenditures are high at the US (for all years) map position (top left of the U- matrix). Note that the U-matrix, in addition to actual grid positions, includes slots between grid positions which are colored to represent how close the grid positions are to one another. The color on an actual grid position represents how close the position is to its neighbors. For example, it is known that the positions of Switzerland and the US (at the top left of the map) are very close in terms of estimated variable values because the hexagon between them is dark blue (very light grey in grey scale format). Conversely, it may be seen that the position occupied by Croatia 92/93 and Latvia 93 (about two thirds of the way down on the left of the map), is distant from its neighbors because it is colored orange (a large distance color, as indicated by the color legend), dark grey in grey scale format.

A study of Figure 2 yields an interpretation - presented on Figure 3 - of the vertical and horizontal dimensions on the map. Together, the visual tools presented in Figures 13 facilitate an overall impression of how the

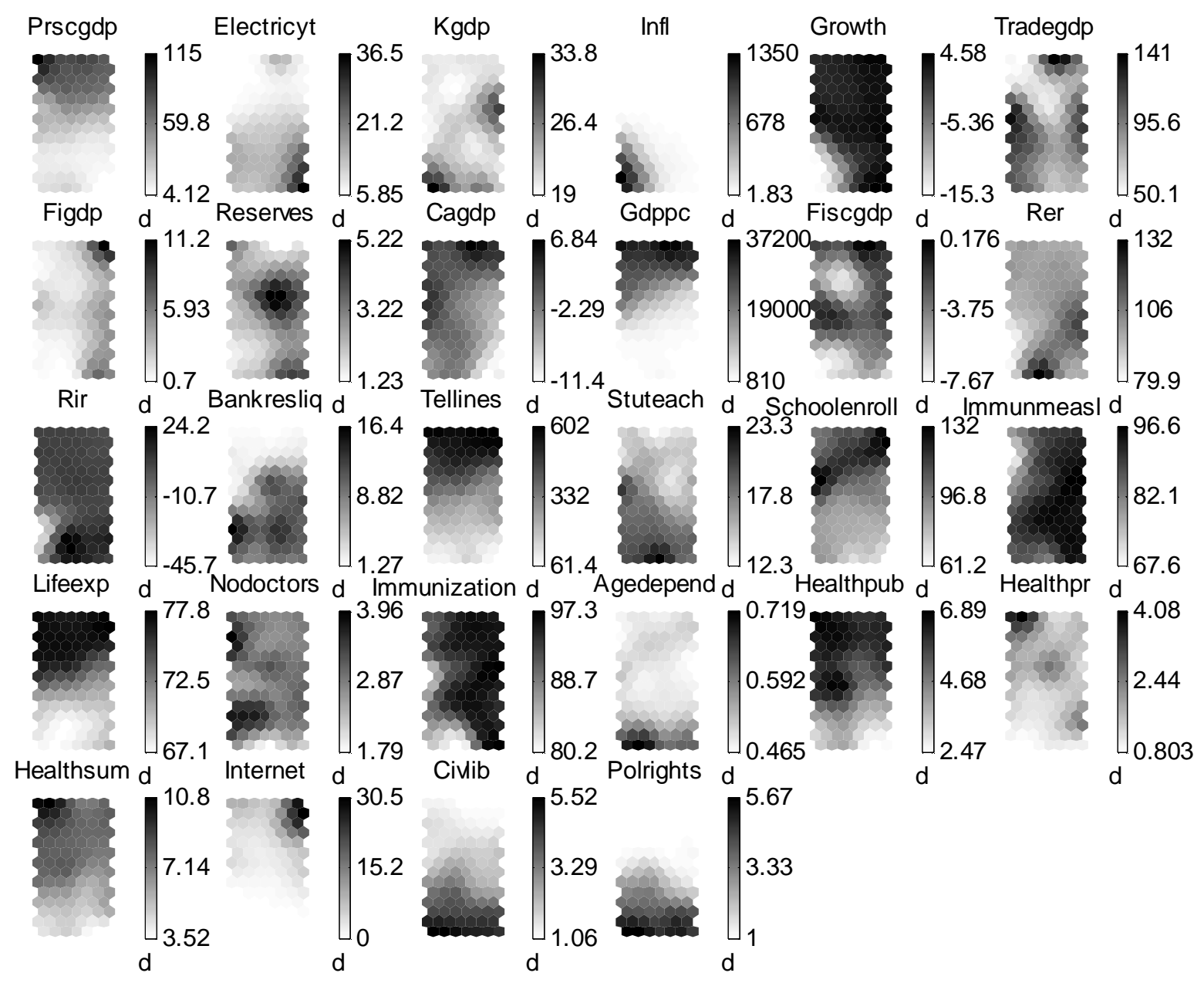

FIGURE 2. COMPONENT MAP OF ALL SOCIOECONOMIC VARIABLES

Note: See http://tbf.coe.wayne.edu/jmasm for map in color. 
countries have fared since 1992 based upon the aggregate set of variables. Although these maps are useful for facilitating a holistic view of multifaceted convergence, they are cumbersome because they include a very complex set of social and economic variables. Accordingly, an analysis of the patterns in detail is not included at this point because they are more efficiently and effectively discussed in the next sections as distinct social and economic dimensions. Instead, Figure 3 is provided as an overarching summary of the main movements of clusters observed in the aggregate U-matrix. From this diagram, it may be asserted that there exists some evidence of positive change throughout Europe. Whether the transition states are indeed converging with the west or simply maintaining positions/falling behind is an issue that is best addressed with specific reference to the identified dimensions.

In an effort to glean a more explicit understanding of the dimensions/axes interpreted in Figure 3, the variables are now subdivided into (mainly) social and economic sub-sets. From these new maps, one may then glean clearer insights on the nature of the SOMs' axes, as well as the extent of convergence along these axes for all Eurasian states in the sample.

Analysis of Social Clusters and Dimensions

In order to evaluate social convergence, this method first identifies clusters of stable states, and then examines movement among clusters and individual states. Figure 4 provides a U-Matrix constructed on the basis of social variables only -infrastructure, health indicators, and political freedom measures, estimated values of which are shown individually in Figure 5. The U-matrix makes it possible to identify several groups, and ultimately combined with an inspection of Figure 5, to identify consistent dimensions and evaluate the degree of convergence over time.

Several groups are identified from Figure 4: a European Core including regionally cohesive sub-groups, the USA, and a former USSR-core state group including Russia, Belarus, and Ukraine. Outside of these groups, very little cohesion exists, and large distances separate each state, most of which tend to move quite substantially over time, with the exception of Turkey, Tajikistan, Armenia, and Albania.

The largest and most cohesive cluster in Figure 4 is the European Core. This includes most of the EU plus, at its edges, the Visegrád states (Czech Republic, Poland, Hungary, and Slovakia), and the Baltics (Estonia, Latvia, and Lithuania). This clustering of EU states with EU candidates is remarkable, underscoring longstanding social similarities that underlie recent economic differences. The clustering together of these states based upon several social variables lends credence to the argument that the Visegrád and Baltic states (formerly of the Warsaw Pact) are truly Western European on a social development level, while also supporting cultural assertions by Rosenbaum (2001).

Within the European Core, separated by sporadic yellow (grey in grey scale format) cells, three somewhat discrete clusters exist: first, a southern/central group (Italy, Greece, Austria, Germany). This group of welfare states is distinguished by a high number of doctors per 1000 population. On this specific measure the EU is similar to the group comprised of Russia, Ukraine, Belarus, and Kazakhstan (see Healthpub in Figure 5) where extensive public health services were extended to the population, a legacy of central planning in the Soviet core area. Second, a recent (late 1990s) Scandinavian group can be identified, distinguished by high levels of internet use, fewer doctors, more teachers, and higher school enrollment levels. Finally, Ireland stands alone throughout much of the decade, but is joined by Spain and Belgium in recent years. Separating these countries from the rest of Europe are larger school classes and much lower immunization rates. The USA is at the top of the social map, but clearly distinct from Europe. Again, by examining Healthpub in Figure 5, one may see how U-matrix positions can be attributed to an extreme estimated score on a specific variable, in this case the diminutive role of government in American healthcare. In association with US isolation on the left side of the U-matrix, this set of observations provides considerable insight for defining the overarching horizontal dimension as individual responsibility (left) versus government welfare (right). 


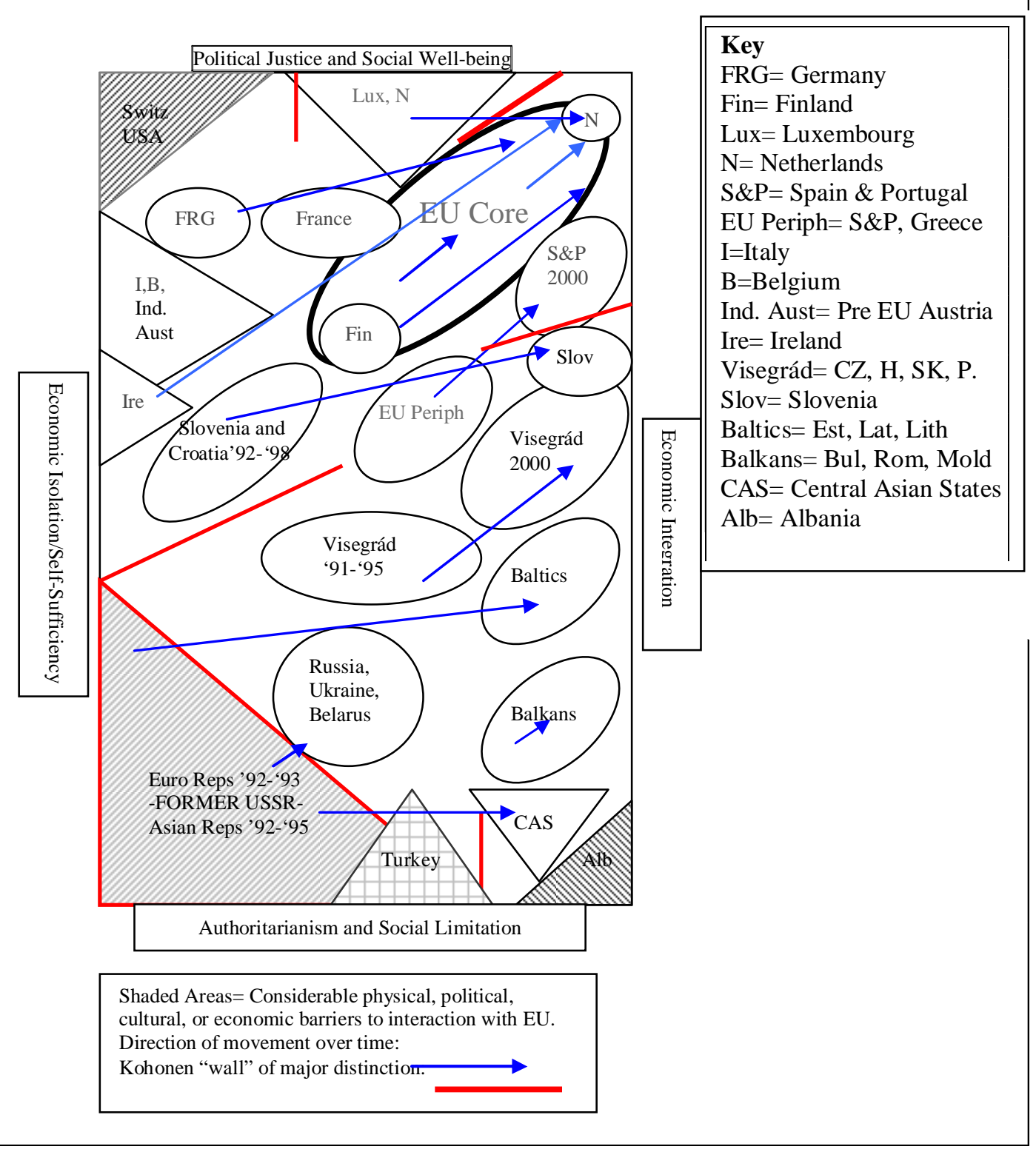

FIGURE 3. ABSTRACTED DIAGRAM OF GROUPS BASED ON FIGURE 1

Note: See http://tbf.coe.wayne.edu/jmasm for map in color. 


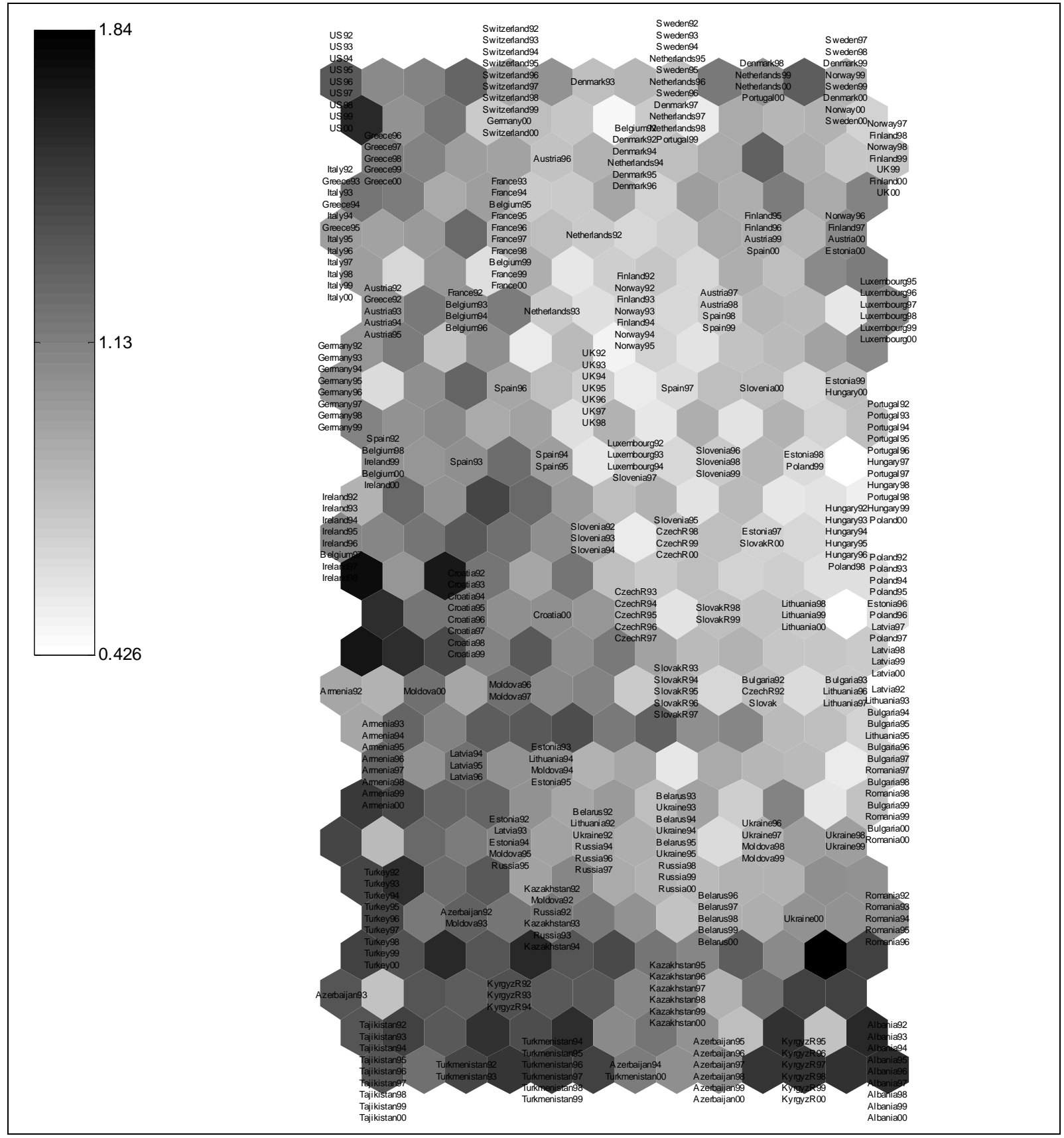

FIGURE 4. U-MATRIX BASED ON SOCIAL INDICATORS Note: See http://tbf.coe.wayne.edu/jmasm for map in color. 


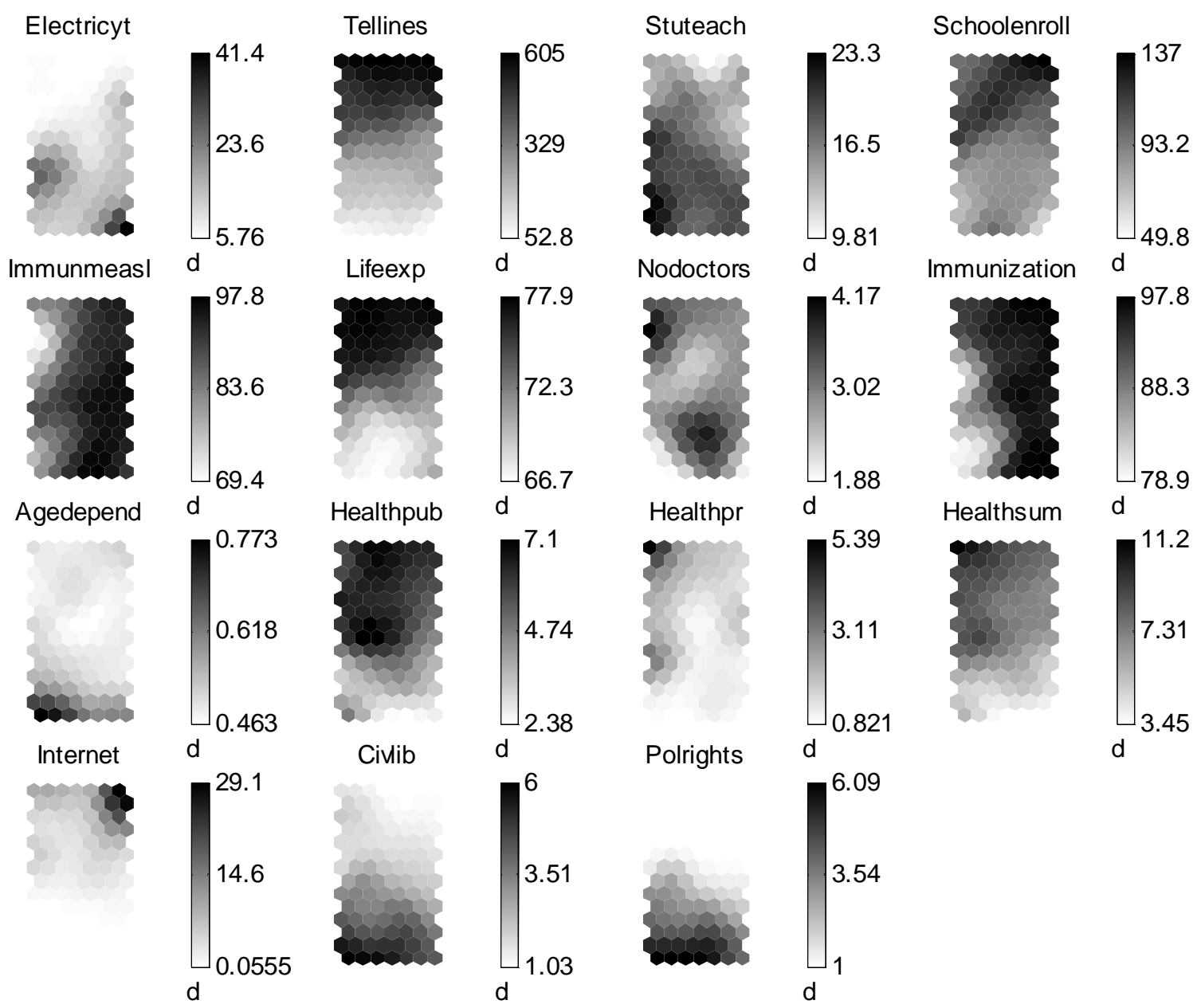

FIGURE 5. COMPONENT MAPS OF CONTRIBUTING SOCIAL VARIABLES

Note: See http://tbf.coe.wayne.edu/jmasm for map in color.

Several countries remain either completely or virtually stable between 1992 and 2000. Sharing few commonalities other than the fact that most of them are not EU-Core, these countries include Switzerland, the USA (our benchmark), Ireland, Turkey, Tajikistan, Albania, and Armenia. Several noteworthy differences were revealed by the estimated variables. First, the position of the US is clearly a result of high private versus public health expenditures, the only social variables in which the US varies notably from the European Core.
This means that although Americans on average enjoy a comparatively high standard of living, they are unique in how much they pay for healthcare. Second, Ireland has fewer teachers and doctors per thousand, and its infrastructure lags behind the European Core. Third, Turkey is isolated from the European Core by low scores on healthcare and education variables, as well as by civil liberties and political rights measures. Fourth, Albania's stability is based upon high scores on democracy, which conflict with inadequate infrastructure (electricity losses) and 


$$
\begin{aligned}
& \text { Higher Quality of Life } \\
& \text { Individual Responsibility } \leftarrow \quad \uparrow \quad \rightarrow \quad \text { Government Welfare } \\
& \text { Lower Quality of Life }
\end{aligned}
$$

FIGURE 6. INTERPRETATION OF SOCIAL DIMENSIONS

poor estimated healthcare and education. Finally, Tajikistan seems to confirm the nature of the horizontal dimension with its high level of age dependency (Figure 5), which draws it to the left side of Figure 4. In drawing this conclusion, it is assumed that birth rates in Tajikistan are higher partially in response to an absence of state social security systems.

Given the aforementioned observations, the horizontal (left-right) dimension is interpreted as a continuum of social individualism vis-à-vis social welfare as exemplified by the relatively less individualistic European Core. Further, the quality of life variables (life expectancy, infrastructure, education, medical care, and political rights) along the vertical dimension lead us to conclude that the quality of life increases as one moves from the bottom to the top of the map (Figure 6).

\section{Convergence on the Social Dimensions}

Overall, the U-matrix of social variables

(Figure 4) indicates relatively less movement than that which is found later on the economic map (Figure 7). This means that little evidence exists for convergence in the social dimension. In order to understand the movements in the map, both the component maps (Figure 5) and the original data file were consulted for dramatic changes in variable values. The largest jump and convergence to Western Europe occurs in Estonia. Although its starting point is similar to that of Latvia, it converges much faster to Europe and by the end of the decade groups together with the periphery European countries such as Portugal. Portugal in turn moves from center-right to top-center during the final two years of analysis due to a major improvement in school enrollment, internet use, and public health expenditures during these years.

Another major movement is that of Germany and Austria, which move from centerleft to top-center in 2000. Austria's improved quality of live appears to be driven by an estimated increase in immunizations, internet use, and doctors, corresponding to the dates following its own EU accession in 1995. Similarly, Figure 5 hints that Germany's improvement is due to increased internet use, measles immunizations, and public health expenditures. This observation confirms a move toward a larger welfare state in Germany, which is in line with Germany's mid-1990s election of a Red-Green alliance government led by Social Democrats.

All of the Visegrád states witness an increase in the quality of life dimension during the final three to four years. Like Germany under the Social Democrats, these fledgling democracies appear to be moving toward the top right, more toward the model of a European welfare state than the individualistic model of the USA or Switzerland. As an example, the Czech Republic enjoyed improvements since 1997 in nearly all social indicators (except school enrollments and immunizations); these changes were faster than the average changes and suggest evidence of social convergence, especially in internet use, public and private health expenditures, availability of doctors, and quality of infrastructure.

Finland and Norway move from the topcenter to the top-right, indicating again a recent improvement in the quality of life, as well as a modest increase in the role of government. This movement appears to be driven primarily by a 
large increase in estimated internet penetration, and an increase in the estimated number of doctors. Several states outside of the European Core show a very gradual horizontal move, but little or no vertical move. One such country is Turkmenistan, showing a gradual sign of improvement in political rights with no change in its quality of life dimension. Azerbaijan and the Kyrgyz Republic show movements similar to Turkmenistan in the political rights dimension; however, this improvement is accompanied by a worsening in the quality of life for both countries. Ukraine and Bulgaria show no evidence of social convergence to the European Core, but both show some modest positive changes on the political rights dimension.

Other countries show no change in the role of government dimension but indicate significant movements in the quality of life dimension. For example, Romania's sheer vertical move indicates improvements in quality of life since 1997. Similarly, Moldova shows no sign of change in its role of government, but it converges to the European criteria in the quality of life dimension, approaching Slovakia and Croatia. Kazakhstan contrasts with Moldova, showing deterioration in quality of life over time, while political rights have improved. Belarus shows signs of similar worsening in quality of life, with very slight improvements in political rights (similar to Kazakhstan).

Three countries - Russia, Latvia, and Lithuania - move along multiple dimensions. Russia has a very gradual increase in the quality of life, providing some evidence of convergence, accompanied by gradual improvements in the political and civil rights. Lithuania also shows similar positive movements, with signs of convergence to Western Europe. Latvia shows a more volatile pattern over the decade, but the end point is very similar to that of Lithuania. They retreat on both dimensions in 1993, but their recovery in 1996 results in net convergence to Western Europe over the decade.

To summarize the maps of social indicators, the European Core and its multiple fringes clearly corresponds to slight variations on Western Civilization (Rosenbaum, 2001; Jordan, 2002). For example, a Scandinavian cluster of welfare states seems to define the epicenter, surrounded by a Germanic cluster (Germany, Austria, Switzerland), a French cluster (France, Belgium), and a group that encompasses the Central European leading transition states (Visegrád and Baltics); this cluster is in slight contrast to the United States, which shares a high quality of life, but prescribes a smaller role for government. When considering these and other examples, considerable stability exists in the social dimensions, indicating that little convergence has occurred. It is likely that the convergence that has occurred in the region hearkens back to cultural linkages that preceded the superficial division of Europe by the Iron Curtain.

Analysis of Economic Clusters and Dimensions

On the basis of the earlier review of the literature (Rosenbaum, 2001), it is expected that economic change can be readily achieved if deeply-rooted cultural and societal values are in place. In an effort to confirm this expectation, Figure 7 was constructed using variables that represent only the economic measures of the states for comparison with Figure 4. The economic U-matrix includes a combination of absolute indicators and change indicators (such as inflation and growth), as well as domestic measures (GDP per capita, reserves) versus measures of international linkages (FDI, trade). 

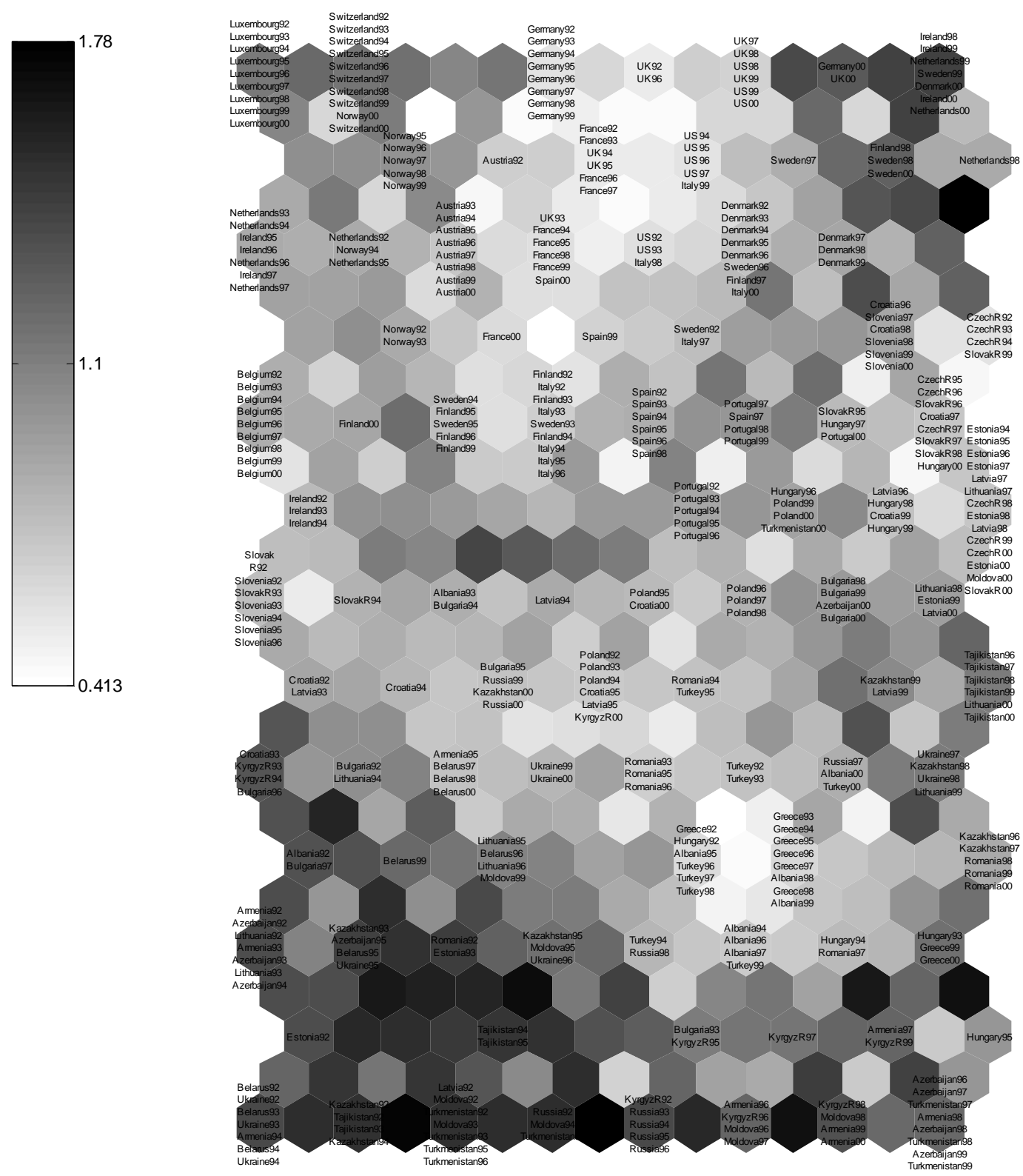

FIGURE 7. U-MATRIX BASED ON ECONOMIC INDICATORS

Note: See http://tbf.coe.wayne.edu/jmasm for map in color. 
In many ways, this U-Matrix is more complex than the U-Matrix of social indicators. First, there is considerably more movement among the countries over time. Second, relatively more barriers exist that distinguish groups from one another, challenging the notion of a cohesive European Core group based upon economic characteristics. The more nebulous nature of this map is likely attributable to the fact that two of the economic variables are measures of rates of change (inflation, growth).

At a basic level, a European Core exists, made up of large EU countries and the US. These are all wealthy countries with plenty of capital-both public and private. Several wealthy, integrated countries with core locations (and geographically close to one another) remain stable throughout the entire period. These include Luxembourg, Belgium, Switzerland, Germany, and Austria. Within this core, a subgroup of countries can be identified in the upperright that experienced exceptional growth at very specific time periods; examples include Ireland 98-2000 and Sweden 98-2000. Ireland's recent growth is widely attributed to relatively inexpensive, well-trained, English speaking labor force and targeted government policies, and the significant foreign direct investment these advantages attracted (see, e.g., Trauth, 2000; 2002).

The transition states are much more volatile on the economic map than on the map of social dimensions. This is unsurprising, as the lifestyles of Europeans, as established on the basis of the social map, are more homogeneous than their economic characteristics. Greece remains fairly stable in the bottom portion of this economic group of peripheral Southern Europe, which is periodically joined by shocktherapy Poland (1992-95), some unstable and rapidly changing former Soviet Republics including Ukraine 1999-2000 and Kazakhstan
2000, as well as Turkey (whose growth efforts are often derailed by economic crises, with correspondingly volatile economic growth) and Albania, which shows rapid change throughout the 1990s in response to far-reaching reforms.

Only a faint barrier distinguishes Europe's core (EU plus Switzerland and USA, minus Spain, Portugal, and Greece) from the transition states (which include the EU's periphery). This lack of clear distinction is attributed to the fact that there is a mixed bag of absolute and relative/change variables. In interpreting the patterns in Figure 7 on the basis of the specific variables in Figure 8, it may be seen that Europe's core has good initial conditions but has experienced less growth and fewer effects of reforms (in particular, growth, real GDP per capita growth).

In contrast to the Core, most transition states had worse initial conditions but have experienced more dramatic growth because of their reforms. As expected, it was found that slow starters converge faster (e.g., Albania, which features some of the worst initial conditions, but is propelled toward the top of Figure 7 by its growth rate throughout the nineties). The position of Turkey, which by comparison was much better off in 1992, remains closer to the bottom partially because of more modest changes since that time and constrained by the real effects of economic crises. These observations corroborate Barro and Sala-i Martin's (1992) assertion that high growth rates can be more easily achieved in economies with less advantageous initial conditions. The nature of economic variables therefore further complicates the position of each state, and in interpreting states' positions close attention should be paid to whether each measure is absolute (e.g., real exchange rate, real interest rate) or an indication of change (e.g., growth, inflation). 


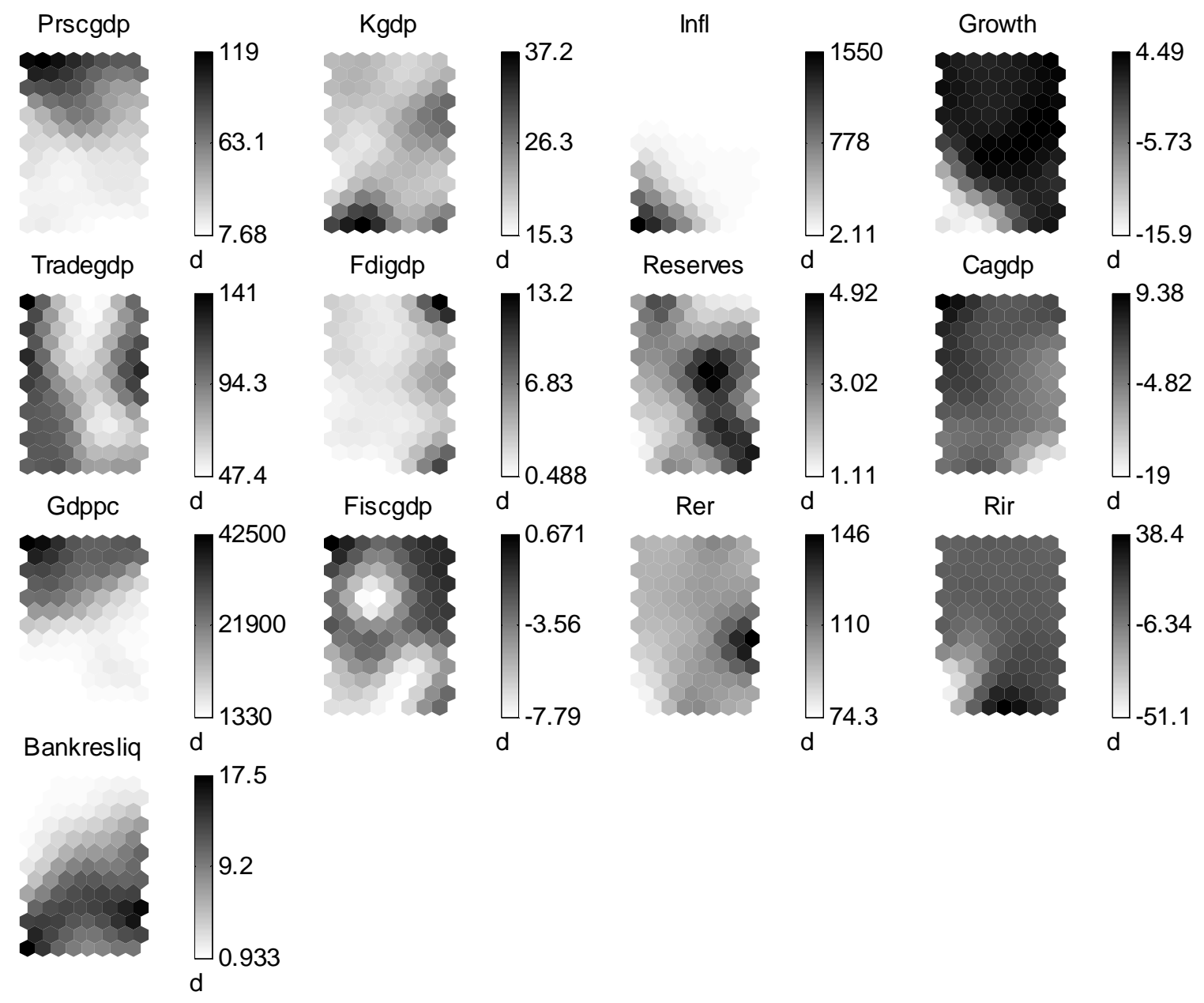

FIGURE 8. COMPONENT MAPS OF ECONOMIC INDICATORS

Note: See http://tbf.coe.wayne.edu/jmasm for map in color.

Convergence on the Economic Dimensions

Movement of countries-both from left

to right and from bottom to top-provide evidence of migration to where the EU core rests, namely at the upper-right corner of the map. The EU core itself moves in this direction over time, as indicated in particular by the movements of the Scandinavian states plus Holland and Ireland. In this northeastwardly direction, the United States and United
Kingdom move toward the top, with the same relative distance between them, and Italy moves toward the Core by itself. Note however the stability of Belgium and Luxembourg over the same period.

The Caucasus, Baltics, and Turkestan (see note 3 in Fig.9) all cover substantial space (even crossing red and yellow cells - very dark and dark cells in grey scale format) during the first few years of the 1990s. This migration 
represents a movement away from historical USSR-oriented trade and toward truly globally integrated trade and investment, which reinforces our interpretation of openness being both on the left and on the right side of the map. Among these states, the most profound moves are in the case of Tajikistan, which had been firmly lodged in the Soviet sphere of influence at the outset of our study (Figure 7), but approaches the Central European success stories by 2000 .

France is a notable exception to the overarching upward trend, moving slightly toward the bottom and left. Similarly, the Czech Republic moves slightly toward the bottom, which is probably indicative of the difficult fiscal conditions during the late 1990s, corroborated by evidence in the component map that points to a shortage of capital. The Czechs responded by looking to FDI to treat their current account deficit since 2000.

Hungary, Estonia, Latvia and Lithuania demonstrate the greatest convergence among the sixteen transition economies in the data, both horizontally toward the right and vertically toward the top. Underscoring this substantial move across Figure 7 is the fact that these states cross a yellowish color (grey in grey scale format) barrier toward Europe, indicating a significant decline in economic distance. Among these four, Hungary is the lone state with a rightside starting point from which it moved vertically upwards. The three Baltic countries show a significant movement away from the other former European Soviet Republics that are concentrated in the lower-left corner.

The remaining countries show either extremely modest convergence or considerable volatility over time. Tajikistan and Kazakhstan show the largest vertical move in this group of eight. Specifically, they move in a mostly northeastward direction, incorporating the convergence features of both the horizontal and the vertical move. Belarus and Ukraine can be grouped together, moving mainly toward the top and right until the late 1990s when the direction seems to shift to the left. This is interpreted as a slowdown in their trajectories of convergence, but it could also be brought on by embracing foreign trade and investment. Armenia,
Azerbaijian, Moldova, and Turkmenistan are propelled by increasing GDP per capita and

growth rates, declining inflation, deeper financial markets, and improved fiscal balances. Moldova seems to have made a late move of convergence after 1998 when it separated from the others in this group. While some progress is evident, this cluster seems to have converged least among the Eurasian states.

The remaining states show considerable volatility. The Kyrgyz Republic demonstrates some of the most volatile movement among transition states, moving to the top and right in 1993-94 and then falling back in 1995, only to jump toward the top again in 2000. Given a lack of data to support this jump the sustainability and the evidence for a continuing convergence is not very clear at this point.

Distinct from the Kyrgyz Republic, but similar in volatility, Turkey and Bulgaria also show considerable circularity in their movements. Turkey is very unique in that it seems to complete a full circle in its move over the past decade. It finishes the decade at its starting point; the 1994 crisis pushes Turkey off the convergence path (toward the bottom of Figure 7) and the recovery brings Turkey back to its initial point with no further evidence for convergence through the end-point of the analysis. While it shows similar circularity during the 1990s, Bulgaria seems to have converged to Europe much more than Turkey.

Romania shows more of a horizontal move to the right, especially in the latter part of the decade. It also converges toward the EU Core significantly in 1994 before retreating again. This observation notwithstanding, Romania seems to be much more open to international goods and capital flows after this period. Finally, Russia's most dramatic period of convergence was 1997 toward the top and right, but following its 1998 economic crisis it returned to its approximate initial level. Russia's leftward movement can also be interpreted as a change toward integration, which lies in marked contrast to Russia's historical policy of autarky (self-sufficiency).

Taking into account the aforementioned movements and subsequent investigation of the component variables and data set, Figure 9 is 
Capital rich- abundant private credit, liquid assets

Economic stability

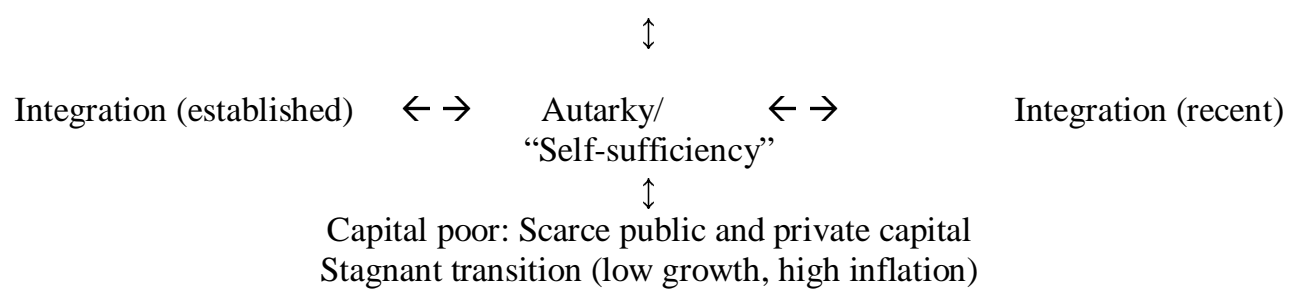

FIGURE 9. INTERPRETATION OF ECONOMIC DIMENSIONS

1 The USA is included in the analysis as a point of reference.

2 To build our Kohonen maps, we used Matlab code (Laboratory of Computer and Information Science at the Helsinki University of Technology), available at www.cis.hut.fi/projects/somtoolbox/.

3Turkestan is the supranational physiographic and cultural region that includes Kazakhstan, Uzbekistan, Turkmenistan, Tajikistan, and Kyrgyzstan —all former Soviet Socialist Republics in Central Asia

presented as a conceptual simplification of the economic dimensions.

As in Figure 6, the labels are based upon the variables that have distinct top/bottom or left/right trends in Figure 8. For example, according to the measure of trade as a share of GDP in Figure 8, the countries on the right and on the left of the map clearly trade more than those in the middle, and the same holds true for FDI as a percentage of GDP; this signifies open (integrated) economies on both the left and the right side of Figure 7. Moreover, bank reserves, reserves, income levels, current account balances and private sector credit all tend to indicate that the top/bottom dimension represents a continuum of capital abundance/capital scarcity.

The meaning of the horizontal axis is less clear than the vertical axis. The right side seems to represent greater capital account openness because FDI as a share of GDP is higher from left to right. But the openness story is less clear when one considers trade as a share of GDP. In any case, the horizontal move seems to capture some of positive aspects of the vertical move as well, because lower inflation is evident when one moves toward the right (and top). Similarly, growth and GDP per capita, FDI as a share of GDP, all increase in that direction, and the fiscal balances improves toward the top and right. This interpretation could suggest that a move toward the right represents a stage in convergence; however, the full convergence occurs if the horizontal move is combined with the vertical move.

Along these lines, Wagner and Hlouskova (2001) also differentiate between convergence and loosely-speaking convergence, where the latter captures convergence in the economic structure of the countries involved on account of strengthened linkages via trade and foreign direct investment.

\section{Conclusion}

This article demonstrates the utility of Kohonen maps for visualizing Eurasian convergence over time $(1992-2000)$ on the basis of 28 socioeconomic measures. It contributes to the literature by identifying and explaining the relative movements of states on a twodimensional map, concurrently taking into account a large number of measures. In past work, measures had to be considered individually when discussing convergence, which explains why past work has to a certain extent led to sometimes conflicting conclusions. This analysis, thus, sheds some light on this debate. 
In addition to the overall analysis that included the aggregate set of variables, the economic and social variables were analyzed separately. The resulting maps demonstrate several differences between the economic and social convergence processes. On one hand, the social variables seem to capture more stable traits of states than economic variables. Interestingly, the 2004 newcomers to the European Union are clearly clustered with most of the rest of the EU in the analysis of social variables, suggesting deeper cultural commonalities between these groups of states.

Nevertheless, there is clearer evidence to support economic convergence than social convergence. It is believed that this is because initial conditions vary, which is particularly evident in the Visegrád states and the Baltics, and to a lesser degree Russia, the other European former Soviet Republics, and the Balkans. This supports the argument regarding the effects of historical and cultural linkages presented by Rosenbaum (2001). This regional gradient of European-ness corresponds to the notion of Brussels distance introduced by Fisher, Sahay, and Végh (1998). Conversely, states that are culturally distant from Western Europe (such as Central Asian Republics or the region known as Turkestan) exhibit less economic convergence.

The main dimensions identified in the analysis suggest major higher-level constructs that can be used in interpretation of the results and potentially also in future research. In the overall analysis, the two major dimensions were the level of political justice and social wellbeing and the extent of economic integration. In the more detailed analyses, the dimensions of the social map were related to the quality of life and the respective roles of governments and individuals in providing social welfare. Finally, the analysis of the economic variables led to the identification of two dimensions related to the timing of economic integration and the availability of capital. Future research should use multiple methods to analyze the relevance of these constructs as well as specific policy reforms.

Methodologically this study demonstrates the usefulness of Kohonen maps to visualize large numbers of variables and complex sets of data in a two-dimensional space.
It was found that the approach of using the stateyear pairs as the basic unit of analysis, originally introduced by Costea et al. (2001), very useful in mapping the time-dependent changes in the relative positions of the states. Future research should pay special attention to the implications of analyzing absolute variables and measures of change, which may have impacted the results of this analysis.

In summary, this article provides an analysis of the socio-economic convergence of Eurasian states with the European Core. It demonstrates the usefulness of Kohonen maps as a tool for analyzing large sets of macroeconomic data over time. The study also distinguishes between economic and social factors, identifying much more proof of the former than the latter. This study identifies and reports indisputable evidence of economic convergence by European transition states that becomes less clear in countries farther to the east. It is argued that such convergence is either facilitated or constrained by preconditions that are either specific to each country or to a broader culture. This article lays the groundwork for further analysis of country-specific reforms and how they interact with initial conditions to impact convergence in the transition states.

\section{References}

Almström, L. (2000, February). What is Europe? The Economist, 12.

Aslund, A., Boone, P., \& Johnson, S. (1996). How to stabilize: Lessons from postcommunist countries. Brookings Papers Economic Activity, 1, 217-291.

Barro, R. J. (1991). Economic growth in a cross section of countries. Quarterly Journal of Economic, 106, 407-443.

Barro, R. J. \& Sala-i Martin, X. (1992). Convergence. Journal of Political Economy. 100(2), 223-251.

Bartlett, D. L. (1997). The political economy of dual transformations: Market reform and democratization in hungary. Ann Arbor, MI: University of Michigan Press.

Jozef, M. B. (1998). Transformation, EU integration, and regional cooperation in eastern Europe. Comparative Economic Studies, 40(4), 33-59. 
Brada, J. \& Kutan, A. (2001). The convergence of monetary policy between candidate countries and the European Union. Economic System, 25, 215-231.

Brada, J. Kutan, A., \& Zhou, S. (2002). Real and monetary convergence within the european union and between the european union and candidate countries: A rolling cointegration approach. (William Davidson Institute Working Papers Series 458, William Davidson Institute, University of Michigan Business School, 2002).

Brezinski, H. \& Fritsch, M. (1996). Bottom-up transformation: Prerequisites, scope and impediments. International Journal of Social Economics, 23(10/11).

Costea, A., Kloptchenko, A., Back, B. (2001). Analyzing economical performance of central-east-european countries using neural networks and cluster analysis. In Ivan, I. \& Rosca, I (eds.), Proceedings of the Fifth International Symposium on Economic Informatics, 1006-1011.

Deboeck, G. (1998, January). Financial applications of self-organizing maps. American Heuristics Electronic Newsletter, 1-7.

Deichmann, J. I., Eshghi, A., Haughton, D., Sayek, S., Teebagy, N., \& Topi, H. (2003). Geography matters: Kohonen classification of foreign direct investment in transition economies. Journal of Business Strategies, 20(1), 23-44.

DeMelo, M., Cevdet, D., \& Gelb, A. (1996). From plan to market. World Bank Policy Research Working Paper No. 1564.

DeMelo, M., Cevdet, D., Gelb, A., \& Stoyan, T. (2001). Circumstance and choice: The role of initial conditions and policies in transition economies. World Bank Economic Review, 15(1), 1-31.

Easterly, W. \& Ross, L. (2003). Tropics, germs, and crops: How endowments influence economic development. Journal of Monetary Economics, 50(1), 3-39.

Ellman, M. (1997). The political economy of transformation. Oxford Review of Economic Policy, 13(2), 23-32.

EBRD (European Bank for Reconstruction and Development, 1999). Transition Report: Ten Years of Transition. London: EBRD.
Estrin, S., Urga, G., \& Lazarova, S. (2001). Testing for ongoing convergence in transition economies, 1970 to 1998. Journal of Comparative Economics, 29, 677-691.

Falcetti, E., Raiser, M., \& Sanfey, P. (2002). Defying the odds: Initial conditions, reforms, and growth in the first decade of transition. Journal of Comparative Economics, 30, 229-250.

Fisher, S., Sahay, R., \& Végh, C. (1998). How far is Eastern Europe from Brussels? International Monetary Fund Working Paper, 98/53.

Freedom House. Annual Freedom in the World Country Scores 1972-73 to 2001-2002. www.freedomhouse.org/research/freeworld/FHS CORES.xls.

Gallup, J. L., Sachs, J. D., Mellinger, A. (1999). Geography and Economic Development. Center for International Development (CID) Working Paper. No. 1.

Genov, N. (1998). Transformation and anomie: Problems of quality of life in Bulgaria. Social Indicators Research, 43(1-2), 197-210.

Ghemawat, P. (2001). Distance still matters: The hard reality of global expansion. Harvard Business Review, September, 2001, 311.

Graham, B. \& Hart, M. (1999). Cohesion and diversity in the european union: Irreconcilable forces? Regional Studies, 33(3), 259-68.

Jordan, T. (2002). The european culture area: A systematic geography. Lanham: Rowman \& Littlefield.

Kaski, S., Kohonen, T. (1995, October). Exploratory data analysis by the self-organizing map: Structures of welfare and poverty in the world. Proceedings of the Third International Conference on Neural Networks in the Capital Markets, London, England, 11-13.

Kloptchenko, A., Back, B., Vanharanta, H., Toivonen, J., \& Visa, A. (2003). PrototypeMatching System for Allocating Conference Papers, Proceedings of the 36th Hawaii International Conference on System Sciences.

Kočenda, E. (2001). Macroeconomic convergence in transition countries. Journal of Comparative Economics, 29, 1-23. 
Kohonen, T. (1982). Analysis of a simple self-organizing process. Biological Cybernet. 44, 135-140.

Kohonen, T. (2001). Self-organizing maps (3rd ed.). Berlin: Springer Verlag.

Krueger, G. \& Ciolko, M. (1998). A note on initial conditions and liberalization during transition. Journal of Comparative Economics, 26, 718-734.

Kutan, A. \& Yigit, T. (2006, in press). Nominal and real stochastic convergence of transition economies. Journal of Comparative Economics.

Lang, I. (2003). Sustainable development: A new challenge for the countries in central and eastern europe. Environment, Development and Sustainability, 5(1-2), 167.

Oja, E. \& Kaski, S. (1999). Kohonen maps. Amsterdam: Elsevier Science.

Popov, V. (2000). Shock therapy versus gradualism ten years down the road. Comparative Economic Studies, 42(3), 121-126.

Rosenbaum, E. F. (2001). Culture, cognitive models, and the performance of institutions in transformation countries. Journal of Economic Issues, 35(4), 889-909.

Romer, P. M. (1986). Increasing returns and long-run growth. Journal of Political Economy. 94(5), 1002-1037.

Sachs, J. D. \& Andrew M. W. (1995). Economic Convergence and Economic Policies, NBER Working Paper Series, No. 5039, 1995.

Sachs, J. The transition at mid-decade. American Economic Review Papers and Proceedings, 86(2), 128-133.
Sachs, J. D. (2001). Tropical underdevelopment. NBER Working Paper Series, No. 8119, 2001.

Skupin, A. (2002, January/February). A cartographic approach to visualizing conference abstracts. IEEE Computer Graphics and Applications, 50-58.

Szalkowski, A. \& Jankowicz, D. (1996). The ethical problems of personnel management in a transition economy. International Journal of Social Economics, 26(12), 14-18.

Trauth, E. M. Using Public Policy to Influence Regional Futures: Lessons from Ireland's Information Economy, www.greatvalley.org/nvc/events/pdf/Eilenn_trau th.pdf.

Trauth, E. M. (2000). The culture of an information economy. Norwell, MS: Kluwer Academic Publishers.

United Nations Economic Commission for Europe (2000, April). Catching up and Falling Behind: Economic Convergence in Europe, UN/ECE News.

Wagner, M. \& Hlouskova, J. (2001). The CEEC10's Real Convergence Prospects. Transition Economics Series, 20.

Woo, W. T. (1998). Improving the performance of enterprises in transition economies. In Woo, W. T., Parker, S., \& Sachs, J. (eds.), Economies in Transition. Cambridge, MS: MIT Press.

World Bank Development Indicators (2002). CD-ROM. Washington, D.C. World Bank. 